\title{
Avanços e retrocessos: a expansão da lavoura canavieira em detrimento da policultura em municípios do Norte Paranaense
}

\author{
Vitor Hugo Ribeiro* \\ Márcio Roberto Ghizzo
}

Resumo: Este artigo tem como objetivo levantar algumas considerações sobre a atividade canavieira no Estado do Paraná, levando em consideração a região Norte e em especial a mesorregião Noroeste Paranaense, localidade onde mais se expande a lavoura canavieira no Paraná. A princípio foi levantado breves considerações entre os vínculos do Paraná com a cana-de-açúcar e, posteriormente, os principais problemas registrados no Norte do Estado em função do aumento da lavoura canavieira. Por fim, foi traçada a problemática que envolve a cana-de-açúcar e o dilema atual pautado na crise alimentar, e a concentração da gramínea em detrimento da policultura e da agricultura familiar.

Palavras chave: Lavoura canavieira. Paraná. Produção de alimentos.

\section{Retrocessions and advances: the extension of the sugarcane crop in the detriment of the polyculture municipalities in the North of Parana.}

\begin{abstract}
This article aims to raise some considerations on the sugar cane cultivation in Paraná State, taking into consideration the North and especially the Northwest Paraná meso-region, place of the fastest growing sugarcane plantations in Paraná. In the beginning it was briefly raised some considerations between the links of Parana with cane sugar and, later, the main problems thet where found in the North of the state due to the increasement of the sugarcane crop. Finally, it was traced the problem involving the sugarcane and the guided current dilemma in the food crisis, and the concentrationof the grass at the expense of mixed polyculture and family farming.
\end{abstract}

Keywords: sugarcane. Paraná. Food production.

\section{Introdução}

A notável expansão do setor sucroalcooleiro brasileiro desencadeada a partir dos anos 1970 e que eclodiu nos últimos anos tem como responsáveis pelo menos dois fatores centrais: o advento das políticas por fontes de energias alternativas que desencadearam os carros com motores à álcool e bicombustíveis 
e a "busca", principalmente dos países desenvolvidos, pela redução da emissão de poluentes na atmosfera. Em outras palavras, é a questão política das novas fontes de energia que vieram substituir os combustíveis fósseis como o petróleo.

O etanol, derivado da cana-de-açúcar, se destaca entre os biocombustíveis inseridos neste contexto. A sua crescente demanda traz consigo uma constante necessidade por novas áreas agrícolas com aptidão para expansão e cultivo desta cultura em todo o Brasil. A área canavieira plantada nos últimos anos, em todo o País, vem crescendo ano a ano, chegando amais de 8 milhões de hectares na safra 2010/11, 9,2\% a mais em relação à safra anterior (SALVADOR, 2010).

Este aumento nas áreas destinadas à produção de cana-de-açúcar nas últimas décadas no Brasil tem origem na implantação do programa brasileiro Proálcool da década de 1970, quando o petróleo teve um aumento significativo de preço, provocado pelas crises do petróleo de 1973 e 1979, gerando uma tensão energética e econômica de âmbito global. Nesse sentido, o governo brasileiro incentivou a implantação de diversas usinas de etanol e a produção de veículos movidos por este combustível.

Este incentivo governamental somado ao novo contexto mundial vem reforçando os focos de tensão no campo, uma vez que a expansão da cana-deaçúcar sobre vastas áreas agrícolas vem agravando as relações entre os pequenos, médios e grandes produtores rurais, principalmente no que tange a acirrada disputa por novas terras para o cultivo. Focos de tensões no campo constantemente são verificados em vários Estados, dentre eles São Paulo, onde concentra majoritariamente a produção canavieira do País. No entanto estes conflitos vêm se expandindo para os demais Estados, dentre eles o Paraná, Minas Gerais e Goiás, dentre outros (RIBEIRO, 2011).

Em especial no Estado do Paraná, além das mobilizações e reivindicações de trabalhadores rurais ocorridas em municípios como Astorga e Porecatu (RIBEIRO, 2009), encontramos também disputas acirradas por arrendamentos de terras entre os demais agentes do agronegócio paranaense, dentre eles da soja, mandioca, laranja, pecuária e outros. A cana-de-açúcar expande-se no Paraná principalmente nestas áreas agrícolas e, com isso, as demais atividades vêm perdendo áreas e diminuindo seus respectivos lucros. Contudo, os principais 
impactos gerados com o avanço da cana-de-açúcar no Paraná e no Brasil em geral ocorrem na agricultura camponesa e familiar.

No geral o avanço da cana-de-açúcar reduz o número de estabelecimentos familiares que apresentam cultivos diversificados, responsáveis principalmente pelo abastecimento do mercado interno com produtos alimentícios de consumo comum como feijão, arroz, mandioca, etc. Isso ocorre principalmente quando os pequenos e médios produtores não dispõem de uma área apropriada para produção da cana-de-açúcar, ou de qualquer outra cultura realmente rentável, restando como alternativa a venda ou o arrendamento de suas terras aos grandes produtores. Dentre as consequências, tem-se a redução da mão-de-obra familiar, dos parceiros e dos empregados permanentes, e um aumento no número de empregados temporários. Em síntese, o número do pessoal ocupado na produção agropecuária se reduz, já que, com o auxílio das máquinas agrícolas, pode-se elevar a produtividade e diminuir a quantidade de trabalho braçal necessário.

Dentro deste esboço, pretendeu-se neste trabalho levantar breves considerações sobre a lavoura canavieira no Estado do Paraná e algumas reflexões acerca da expansão desta atividade, principalmente no que diz respeito ao Norte Paranaense, espacialidade onde se concentra a cultura e as agroindústrias canavieiras. Como parâmetro metodológico, foram utilizados dados quantitativos de áreas agrícolas destinadas à cana-de-açúcar e, com isso, foram gerados mapas temáticos bem como imagens de satélites que nos auxiliaram no tratamento da problemática em questão.

\section{Os vínculos entre a cana-de-açúcar e o Estado do Paraná}

Embora tenha se intensificado nas últimas décadas, não é recente que o Paraná mantém vínculos com a atividade canavieira. A história da cana-de-açúcar no Estado paranaense começou logo nos séculos XVI e XVII, quando esta atividade apareceu no Brasil nos princípios da ocupação portuguesa. Contudo, o Paraná pouco acrescentou no ciclo econômico açucareiro que vigorou nos primeiros séculos de colonização do País, além de fornecer aos engenhos nordestinos mão-de-obra indígena para a monocultura da cana-de-açúcar (RIBEIRO, 2008). 
Neste período histórico da cana-de-açúcar no Paraná, os derivados da mesma destinavam-se à fabricação de aguardentes, comercializados no âmbito local do município de Antonina principalmente, região litorânea do estado. Todavia, a produção dos derivados da cana-de-açúcar restringiu apenas às localidades litorâneas, e a atividade não desenvolveu forças, na época, para competir com a produção nordestina. Além disso, em todo o período do Brasil colonial onde a cana-de-açúcar foi uma das principais atividades econômicas, no Paraná outros ciclos econômicos apareceram e tiveram maior importância, como o tropeirismo e a pecuária, a extração de erva mate e madeira, dentre outros. Neste caso, a atividade canavieira foi deixada sempre em segundo plano, restringindo apenas às localidades citadas anteriormente. Num período mais recente, com a criação do Instituto do Açúcar e do Álcool (IAA), cujo objetivo era o financiamento às agroindústrias do setor para produzir açúcar e álcool, na década de 1940, no Norte do Paraná a cultura canavieira ocupou determinados espaços agrícolas, principalmente depois da instalação das usinas de açúcar Bandeirantes, Central do Paraná e Jacarezinho. Nesse momento, segundo Meneguetti (1988, p. 139) a cultura da cana-de-açúcar ingressou no Paraná pelo Norte Pioneiro, ocupando áreas nos municípios vizinhos do Estado de São Paulo, como Jacarezinho, Cambará, Andirá, Bandeirantes, Porecatu entre outros, onde se instalaram as primeiras usinas de açúcar.

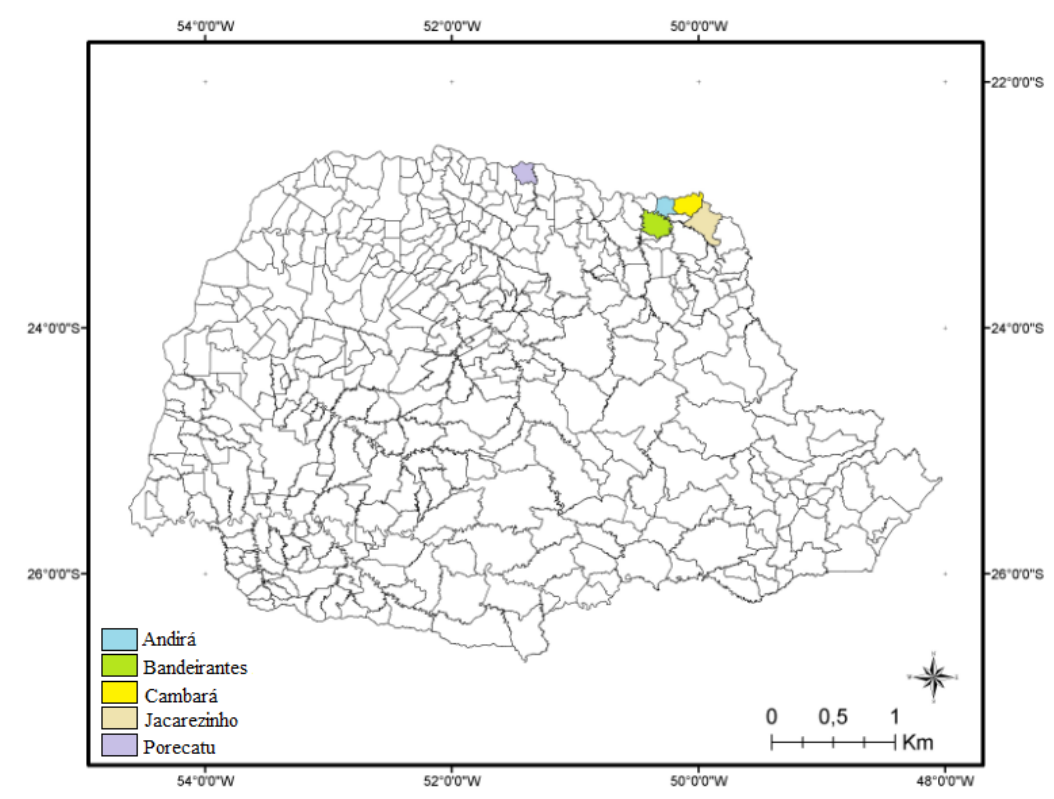
Mapa 1: Estado do Paraná, localização geográfica das primeiras áreas canavieiras do Norte do Paraná
Fonte: Ribeiro, 2008.

Adaptado: Ribeiro, 2011. 
O mapa anterior apresenta a localização geográfica dos primeiros municípios contemplados com usinas na época da criação do IAA, que foram Jacarezinho, Bandeirantes e Porecatu com a Central do Paraná. Percebe-se que, desde então, a cana-de-açúcar vem se expandindo ao longo do norte do Estado. Dentre os municípios citados, apenas Porecatu não compreende a mesorregião Norte Pioneiro, e sim Norte Central Paranaense. Com o advento do IAA, a cultura canavieira vem se regionalizando territorialmente no Norte do Paraná em função das características geo-físicas desta porção do Estado, que apresenta as condições ideais para a realização da atividade canavieira, pois é compreendida na sua maior parte por um relevo suavemente ondulado, propício à mecanização, além de compreender a parte do Estado no qual predomina o clima tropical.

Os solos da região também favorecem o cultivo da cana-de-açúcar, devido as terras roxas e férteis. $\mathrm{Na}$ área de solo arenoso, do noroeste paranaense, a cana-de-açúcar também se adaptou e atualmente é a localidade onde mais se expande esta atividade no Paraná, como será tratado mais adiante. Além dos fenômenos geofísicos, importante citar também a atuação dos agentes do agronegócio e a sua força no Norte Paranaense, conhecidos no âmbito econômico de nível nacional e, muitas vezes, internacional com a exportação de suas commodities, especialmente o soja, trigo e milho. Nas últimas décadas a cana-de-açúcar vem ocupando áreas agrícolas destes e outros cultivos, e a busca pelos arrendamentos de terras no norte paranaense vem causando conflitos entre os demais agentes do agronegócio (RIBEIRO, 2011).

Ainda dentro do contexto da criação do IAA, dentre os principais motivos muitas vezes ressaltados, foi em virtude da Segunda Guerra Mundial e a dificuldade no período de comercializar os derivados da cana-de-açúcar pelo Atlântico (TEIXEIRA, 1988). Contudo, vale lembrar também que neste período o parque industrial brasileiro dava os seus primeiros passos, concentrando-se, especialmente, na região sudeste do Brasil. Isso levou as políticas públicas estatais à um olhar mais atento acerca dos meios energéticos do País, para prover de energia as indústrias que iam se criando desde então (IANNI, 1965).

Outro período importante na história da economia canavieira no Brasil foi a criação do Programa Nacional do Álcool (Proálcool) na década de 1970 em 
função da crise energética global, onde o Governo brasileiro necessitou investir em novas fontes de energias para suprir a demanda do petróleo que o País dependia na época. O Proálcool deu um novo impulso à economia canavieira com incentivos e recursos para a construção de novas usinas e destilarias. Com isso, o complexo canavieiro se concentrou no centro sul do País, onde se encontra atualmente os principais Estados produtores dos derivados da cana-de-açúcar do Brasil.

Em se tratando do Estado do Paraná, após a implementação do Proálcool, cresceu o número de usinas e destilarias, não restringindo mais às áreas tradicionais do Norte Pioneiro como já citado anteriormente. Ao longo das décadas de 1960/70, já tivera no Paraná projetos e construções de unidades de produção do Setor Sucroalcooleiro. Com o Programa Nacional do Álcool, esta atividade se intensificou e o número de unidades ampliou, expandindo-se para municípios do Norte Central e Noroeste Paranaense (RIBEIRO, 2011).

A tabela a seguir apresenta as destilarias de álcool que estavam em funcionamento no Estado do Paraná no ano 2000. Percebe-se que ocorreu um aumento expressivo de destilarias autônomas no período de 1980-1986, quando da segunda fase do Proálcool decorrente da aceleração do setor sucroalcooleiro com o crescimento da frota de veículos movidos especialmente a álcool. 
Tabela 1- Destilarias de Álcool em Atividade no Estado do Paraná- 2000

\begin{tabular}{|c|c|c|c|}
\hline DESTILARIA & MUNICIPIO & TIPO (*) & ANO ATIVID. \\
\hline Bandeirantes & Bandeirantes & Anexa & $1970 / 71$ \\
\hline Central Paraná & Porecatu & Anexa & $\begin{array}{l}1970 / 71 \\
1970 / 71\end{array}$ \\
\hline $\begin{array}{l}\text { Santa } \\
\text { Terezinha }\end{array}$ & Maringá & Anexa & $1971 / 72$ \\
\hline Casquel & Cambará & Autôn./ anexa: 00 & $1977 / 78$ \\
\hline Damisa & Santo A. Platina & Autônoma & $1978 / 79$ \\
\hline $\begin{array}{l}\text { Alto Alegre } \\
\text { Goioere } \\
\text { Santa Laura }\end{array}$ & $\begin{array}{c}\text { Colorado } \\
\text { Moreira Sales } \\
\text { Ibaiti }\end{array}$ & $\begin{array}{c}\text { Autôn./anexa: } 91 \\
\text { Autôn./anexa: } 95 \\
\text { Autônoma }\end{array}$ & $\begin{array}{l}1979 / 80 \\
1980 / 81 \\
1980 / 81\end{array}$ \\
\hline $\begin{array}{l}\text { Copagra } \\
\text { Dacalda }\end{array}$ & $\begin{array}{l}\text { Nova Londrina } \\
\text { Jacarezinho }\end{array}$ & $\begin{array}{l}\text { Autônoma } \\
\text { Autônoma }\end{array}$ & $\begin{array}{c}1981 / 82 \\
81 / 82\end{array}$ \\
\hline $\begin{array}{l}\text { Usaciga } \\
\text { Cocafé }\end{array}$ & $\begin{array}{l}\text { Cidade Gaúcha } \\
\text { Astorga }\end{array}$ & $\begin{array}{c}\text { Autôn./ anexa: } 94 \\
\text { Autônoma }\end{array}$ & $\begin{array}{l}83 / 84 \\
83 / 84\end{array}$ \\
\hline $\begin{array}{l}\text { Cocari } \\
\text { Cooperval }\end{array}$ & $\begin{array}{c}\text { Marialva } \\
\text { Jandaia do Sul }\end{array}$ & $\begin{array}{c}\text { Autônoma } \\
\text { Autôn./ anexa: } 96\end{array}$ & $\begin{array}{l}83 / 84 \\
83 / 84\end{array}$ \\
\hline $\begin{array}{l}\text { Corol } \\
\text { Cotal }\end{array}$ & $\begin{array}{l}\text { Rolandia } \\
\text { Tapejara }\end{array}$ & $\begin{array}{c}\text { Autôn./ anexa: } 93 \\
\text { Autônoma }\end{array}$ & $\begin{array}{l}83 / 84 \\
83 / 84\end{array}$ \\
\hline Covapi & Paranacity & Autônoma & $83 / 84$ \\
\hline Melhoramentos & Jussara & Autônoma & $83 / 84$ \\
\hline Coopcana & São C. Ivaí & Autônoma & $83 / 84$ \\
\hline $\begin{array}{l}\text { Vale do Ivaí } \\
\text { Dail }\end{array}$ & $\begin{array}{l}\text { S. Pedro do Ivaí } \\
\text { lbaiti }\end{array}$ & $\begin{array}{c}\text { Autôn./ anexa: } 93 \\
\text { Autônoma }\end{array}$ & $\begin{array}{l}83 / 84 \\
84 / 85\end{array}$ \\
\hline Americana & Nova Am.da Colina & Autônoma & $84 / 85$ \\
\hline Coamo & Campo Mourão & Autônoma & $85 / 86$ \\
\hline Sabarálcool & Eng. Beltrão & Autôn./ anexa: 93 & $85 / 86$ \\
\hline Coamto & São Tomé & Autônoma & $86 / 87$ \\
\hline Cofercatu & Porecatu & Autôn./ anexa: 93 & $86 / 87$ \\
\hline Coocarol & Rondon & Autônoma & $86 / 87$ \\
\hline Julina & Tapejara & Autôn./ anexa: 93 & $86 / 87$ \\
\hline São José & Paranacity & Autôn./ anexa: 94 & $86 / 87$ \\
\hline Cocamar & Maringá & Autônoma & $87 / 88$ \\
\hline Mideçu & Mandaguaçú & Autônoma & $88 / 89$ \\
\hline Ivaté & Ivaté & Autôn./ anexa: 96 & $88 / 89$ \\
\hline Perobalcool & Umuarama & Autôn./ anexa: 98 & $89 / 90$ \\
\hline Nova Produtiva & Astorga & Autônoma & $99 / 00$ \\
\hline
\end{tabular}

Fonte: TEIXEIRA, 2002.

Na medida em que se ampliava o número de unidades de produção (usinas e destilarias), aumentavam também as áreas agrícolas destinadas a cana-deaçúcar. É possível observar, na próxima tabela, o aumento da produção e da área plantada da lavoura canavieira, e desde o Proálcool, mesmo se passando por algumas crises locais, a cana-de-açúcar continua em expansão no Estado Paranaense (RIBEIRO, 2011).

Percebe-se o aumento da área ocupada com cana-de-açúcar no Paraná nos anos procedentes ao Proálcool. Essas informações foram apresentadas apenas para se ter uma noção do crescimento do ramo sucroalcooleiro paranaense após o programa. Demais informações mostram como rapidamente 
ficam desatualizados estes dados tendo em vista a dinâmica que se observa com o setor agroindustrial canavieiro na atualidade.

Tabela 2 - Paraná, Evolução da Área e da Produção Canavieira, 1972-2000.

\begin{tabular}{lcc}
\hline \multicolumn{1}{c}{ Safra } & $\begin{array}{c}\text { Área Plantada } \\
\text { (ha) }\end{array}$ & Produção (t) \\
\hline $1972 /$ & 46.987 & 2.322 .569 \\
73 & & 2.605 .564 \\
$1975 /$ & 52.000 & 3.375 .000 \\
76 & & \\
$1978 /$ & 45.000 & 6.840 .000 \\
79 & & 10.425 .000 \\
$1981 /$ & 90.000 & 11.856 .032 \\
82 & 140.878 & 14.219 .580 \\
$1984 /$ & 157.355 & 15.945 .937 \\
85 & 172.280 & 24.563 .963 \\
$1987 /$ & 215.856 & \\
88 & 300.070 & 22.120 .000 \\
$1990 /$ & & \\
91 & 325.287 & \\
$1993 /$ & & \\
94 & & \\
$1996 /$ & & \\
97 & & \\
$1999 /$ & & \\
2000 & &
\end{tabular}

Fonte: Ribeiro, 2008.

Essa dinâmica vem acontecendo não apenas no Paraná, mas também em outros Estados Brasileiros como em Goiás, Minas Gerais, Mato Grosso, Mato Grosso do Sul e dentre outros. O setor canavieiro, concentrado no Estado de São Paulo principalmente, tende a aumentar a sua influência nas demais localidades citadas anteriormente, motivados principalmente pelo Zoneamento Agroecológico da Cana-de-açúcar no Brasil, que tem como parâmetro crucial estudos sistêmicos acerca da gramínea (cana-de-açúcar) em áreas agrícolas que apresentem aptidões favoráveis ao cultivo da mesma (RIBEIRO; ROCHA, 2009).

No Estado do Paraná, a cana-de-açúcar tem o seu zoneamento agroecológico territorializado do Norte do Estado, localidade onde predomina o clima tropical favorável ao desenvolvimento da gramínea. A imagem a seguir apresenta a distribuição da lavoura canavieira nesta região, sendo possível perceber que a cultura ocupa quase a totalidade de muitas áreas municipais do setentrião paranaense. Essa concentração canavieira numa zona agrícola de um determinado município vem acontecendo em diversas regiões do Brasil. Dentre os principais efeitos negativos dessa concentração, é o detrimento da policultura e 
da agricultura familiar tão importante para o desenvolvimento de muitas localidades, além também de manter o homem, o trabalhador rural, em seu ambiente (RIBEIRO, 2011).

No Paraná esses efeitos são visíveis há décadas, principalmente no Norte do Estado onde se concentra as principais empresas do ramo agroindustrial, e tem se intensificado nos últimos anos com a expansão da atividade canavieira na região, a qual pode ser evidenciada no mapa 02 que representa a atual distribuição desta cultura.

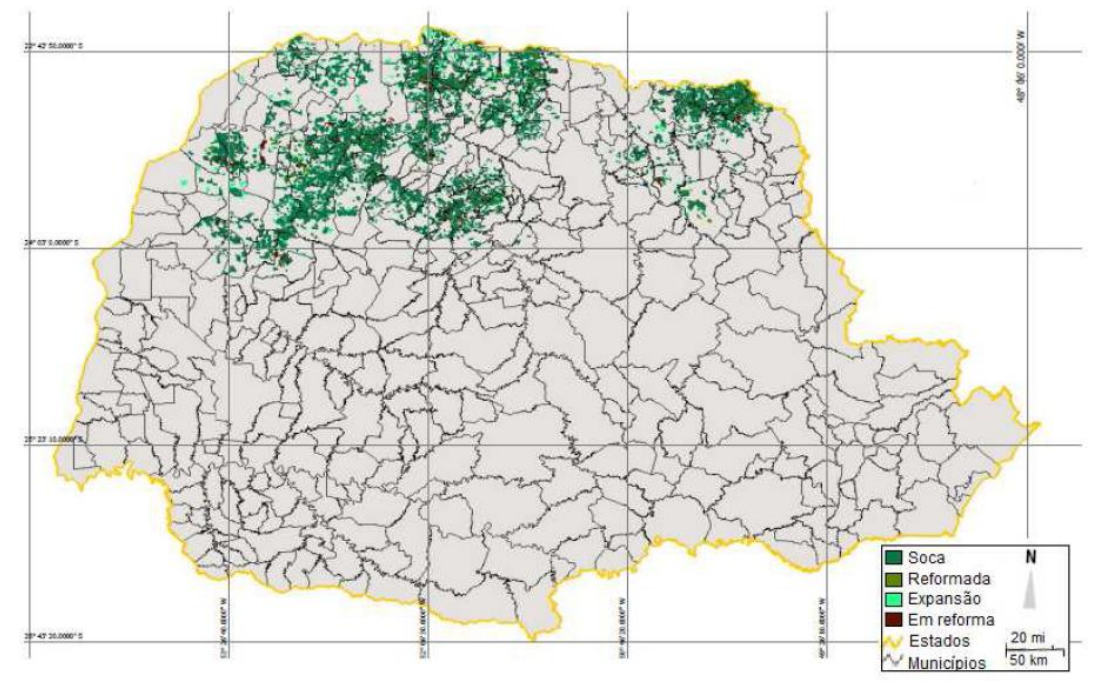

Mapa 2- Distribuição da Lavoura canavieira no Estado do Paraná, 2009.

Fonte: Ribeiro, 2011.

Em diversos textos do professor Milton Santos, dentre eles a Economia Espacial (2007) e A Natureza do Espaço (2006), o autor abordava que para as atividades industriais se beneficiarem no bojo do modo de produção capitalista dentro de um determinado território, é importante a presença das firmas próximas às matérias-primas, facilitando e diminuindo os custos com meios de transportes e demais sistemas de comunicação. Com o agronegócio canavieiro não é diferente: as usinas e destilaria, ou seja, o complexo agroindustrial canavieiro também se concentra no Norte do Paraná em função da proximidade da matériaprima (cana-de-açúcar), bem como pode-se observar no mapa 3. Esse assunto acerca do setor sucroalcooleiro do Paraná também foi estudado pela Endlich (2009) quando a autora abordou temas sobre as pequenas cidades do noroeste paranaense, algumas delas tendo como principal atividade econômica a cana-deaçúcar. 
Assim, a lavoura canavieira tem produzido e re-produzido o espaço geográfico no Norte do Paraná com as suas agroindústrias, e modificando a paisagem rural e urbana da região. Tamanha a dinâmica do agronegócio canavieiro no setentrião paranaense, que muitas unidades de produção mobilizam trabalhadores de diversas localidades do país, dentre elas os Estados de Minas Gerais, Bahia e Alagoas, entre outros (RIBEIRO, 2011).

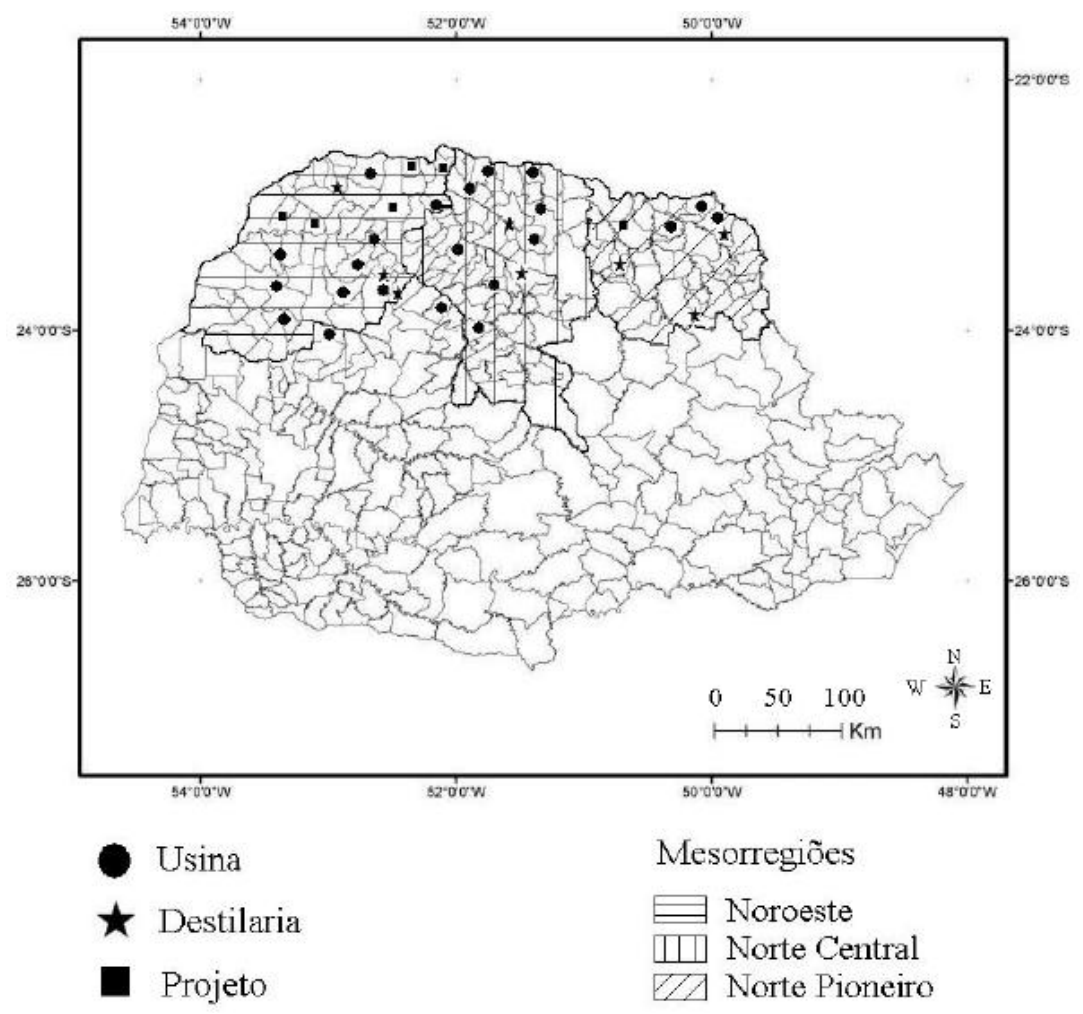

2008.

Mapa 3- Localização das Unidades de Produção de açúcar e álcool do Paraná, Fonte: Ribeiro, 2011.

O mapa 3 apresenta a distribuição das usinas e destilarias do Paraná no ano de 2008. Cabe lembrar que os projetos em construção já estão em atividades nas suas respectivas mesorregiões. A mesorregião Noroeste é a localidade do Paraná que mais concentra unidades de produção do ramo sucroalcooleiro, além também de ser a localidade onde mais se expande a lavoura canavieira. Os dados organizados na tabela a seguir mostram alguns números da produção canavieira no Noroeste Paranaense e no estado em geral, e a perspectiva no futuro é a expansão e concentração da cana ainda mais nesta localidade. 
Tabela 3- Paraná, Norte Paranaense e produção canavieira por mesorregiões.

\begin{tabular}{l|r|r|c}
\hline \multicolumn{1}{c|}{ Mesorregião Geográfica } & $\begin{array}{c}\text { Quantidade } \\
\text { Produzida (t) }\end{array}$ & $\begin{array}{c}\text { Área Plantada } \\
\text { (Hectares) }\end{array}$ & $\begin{array}{c}\text { Área Colhida } \\
\text { (Hectares) }\end{array}$ \\
\hline Noroeste Paranaense & 25.216 .167 & 280.376 & 280.376 \\
Norte Central Paranaense & 13.915 .782 & 159.382 & 159.382 \\
Norte Pioneiro Paranaense & 10.411 .960 & 107.828 & 107.828 \\
Total do Norte Paranaense & 49.543 .909 & 547.586 & 547.586 \\
Paraná Total & 53.831 .791 & 595.371 & 595.371 \\
\hline
\end{tabular}

Fonte: IBGE, 2011.

Elaboração: Ribeiro, 2011.

Percebe-se que, em 2009, o Norte Paranaense produziu 49.543.909 toneladas de cana-de-açúcar, aproximadamente $93 \%$ da produção total do Estado. Em se tratando de área plantada, os 547.586 hectares ocupados pela cana-de-açúcar no setentrião paranaense representam 92\% de todo o Paraná. Outra mesorregião que pratica esta atividade, porém não tão dinâmica quanto as mesorregiões mencionadas na tabela, é a Centro Ocidental Paranaense, que provém de apenas uma Unidade de produção localizada no município de Moreira Sales. Esta mesorregião cultivou em 2009 aproximadamente 36.691 hectares de cana-de-açúcar, 6,2\% da área canavieira do Estado. Sua quantidade produzida em 2009 chegou aos 3.672 .406 toneladas, apenas $6,8 \%$ da produção paranaense.

As demais localidades que cultivam a cana-de-açúcar são aquelas onde os derivados da mesma destinam-se à fabricação de aguardentes, e outros consumos destinados ao comércio local. Na região litorânea do Paraná, por exemplo, ainda se encontra alguns municípios que praticam esta atividade. Porém a produção canavieira não é utilizada para a fabricação de açúcar e álcool em agroindústrias. Já no norte paranaense, onde se localiza o complexo agroindustrial canavieiro, a produção de açúcar e de álcool é destinado ao consumo interno e também externo, para outros países como os asiáticos (RIBEIRO, 2011). 


\section{O Zoneamento Agroecológico da Cana-de-açúcar e as suas implicações no Estado do Paraná: um olhar para o Noroeste Paranaense}

Atualmente, a principal política pública do Governo Federal para expandir a lavoura canavieira no Brasil é o desenvolvimento do Zoneamento Agroecológico da Cana-de-açúcar. O Ministério da Agricultura (2009) levou em consideração o potencial pedológico, considerando seis fatores que limitam o cultivo da cana-deaçúcar: deficiência de fertilidade, deficiência de água, excesso de água ou deficiência de oxigênio, suscetibilidade à erosão, impedimentos à mecanização e impedimento ao sistema radicular. Além dessas, a declividade do relevo também foi levada em consideração e as áreas com declividade superior a $12 \%$ foram excluídas das áreas favoráveis ao cultivo da gramínea.

Levando-se em conta esses fatores, o Brasil dispõe aproximadamente 64,7 milhões de hectares de áreas aptas à expansão da lavoura canavieira. $O$ zoneamento excluiu a expansão na região do pantanal e na Amazônia legal, pelo menos "na teoria". Isto porque, torna-se necessário acompanhar na prática se isso será realmente fiscalizado, uma vez que o zoneamento permite a expansão da cana-de-açúcar no centro-sul do país e em alguns estados do norte como Tocantins e Maranhão.

No Estado do Paraná, as áreas mais propícias investigadas pelo zoneamento localizam-se no norte e no litoral, regiões do Estado onde predominam o clima tropical. Nas demais regiões, o clima subtropical frio e as áreas serranas desfavorecem o cultivo da cana-de-açúcar. Neste caso, diversos agentes do agronegócio do setentrião paranaense já tomaram providencias em relação à expansão da cana, uns buscando créditos e financiamento do Estado para manter os arrendamentos de terras, outros justificando que a expansão da cana se dá em áreas produtoras de outras atividades agrícolas. Prefeitos da mesorregião Norte Pioneiro, em 2008, se mobilizaram contra essa expansão, alegando que isso poderia "trazer pressões sobre novas áreas de grãos ou reduzir a área de pecuária", conforme evidenciado na figura 01. (MARTINS, 2008). 


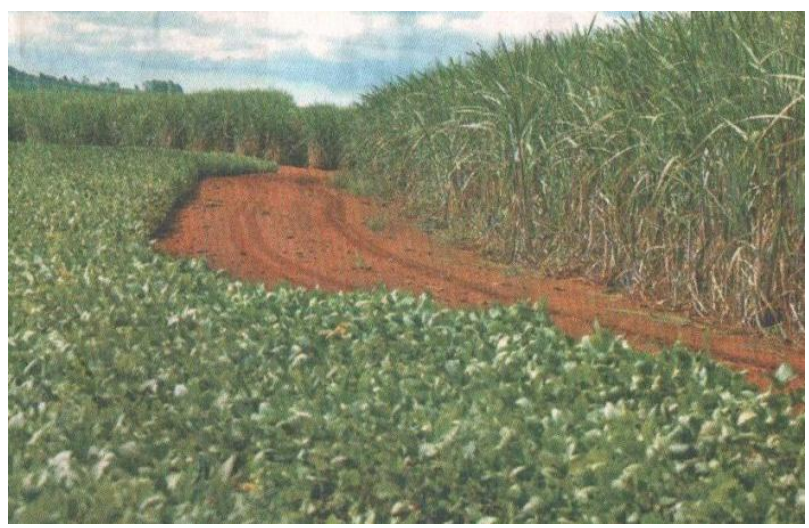

Figura 1- Soja e cana lado a lado, na disputa por espaço no Paraná. Fonte: Martins, 2008

Na mesorregião Noroeste, além da pecuária, a cana-de-açúcar expande-se pelas áreas agrícolas ocupadas pela mandiocultura. Isso fez com que nos últimos anos empresários do ramo buscassem créditos e subsídios estatais para manter seus arrendamentos e garantir áreas para a produção das safras seguintes (RIBEIRO, 2008). Percebe-se que, nestes dois casos, houve mobilização dos agentes sociais dominantes da agricultura paranaense.

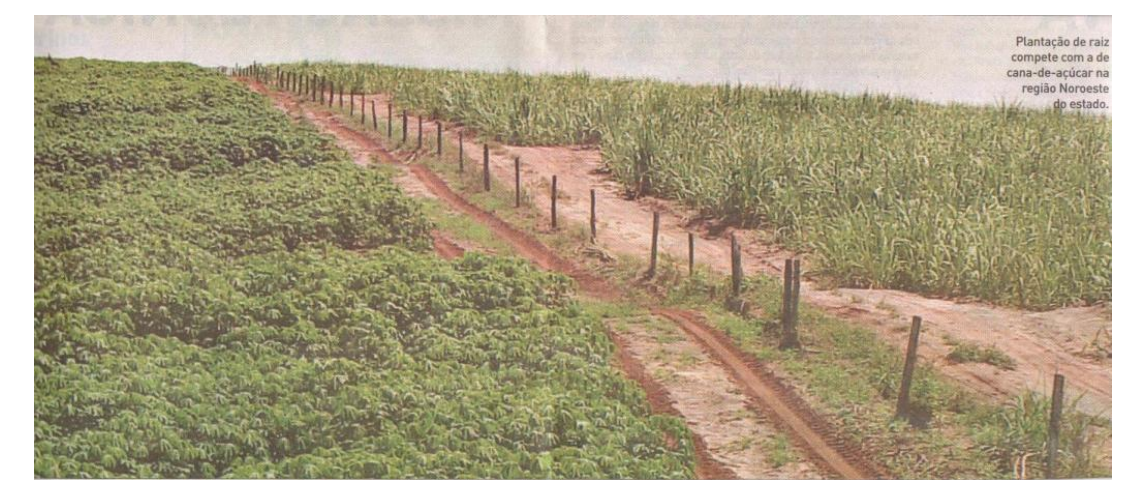

Figura 2- Plantação de raiz compete com a de cana-de-açúcar na Região Noroeste do Paraná Fonte: Osmar Nunes, Gazeta do Povo.

Contudo, não são apenas estes os agentes responsáveis pela cadeia produtiva sucroalcooleira. É bom frisar que esta atividade se reproduz às custas do trabalho exaustivo e precarizado do homem do bóia-fria. São centenas de trabalhadores mobilizados por dezenas de usinas e destilarias diariamente, trabalhando, muitas vezes, há mais de cem quilômetros de distância do seu município de origem (RIBEIRO, 2011).

Além da precarização das relações de trabalho, importante ressaltar também a expansão da cana-de-açúcar em detrimento da agricultura familiar e da 
policultura. Muitos pequenos e médios proprietários rurais estão arrendando suas terras para os agentes canavieiros, com isso diminui-se a produção destinada à alimentação humana (RIBEIRO, 2011). Em especial no Noroeste paranaense, um dos motivos que vem contribuindo com essa expansão é o fato do arrendamento ser mais lucrativo para os pequenos e médios agricultores. Os problemas em função do solo arenítico da região, juntamente com a descapitalização destes agricultores, condicionam essa prática para as usinas. Segue o depoimento de um sindicalista da mesorregião Noroeste:

veja o lado do agricultor que tem lá, 10 alqueires de terras e com esse solo degradado que ta, e descapitalizado, ele vai conseguir manter lá umas 50 a 60 cabeças de gado. Isso ai ele vai tirar o leite, ou vai produzir a carne. Então, a renda é pequena. Se você tem 10 alqueires, e é entre 1000 a 1400 a renda por alqueire, o proprietário vai tirar livre, livre sem se preocupar com nada, entre 10 mil a 14 mil reais por ano. Ai ele vai fazer outra atividade (Apud RIBEIRO, 2011).

Percebe-se na fala do sindicalista, que muitas vezes as condições naturais pedológicas da região vêm corroborando os arrendamentos das usinas. Muitos pequenos e médios agricultores preferem arrendar suas terras para a cana-deaçúcar do que para as outras atividades como a mandioca, pois a cana alcança um preço maior no arrendamento. Esse fato merece atenção, pois são principalmente das pequenas e médias propriedades que provém os alimentos da mesa do brasileiro (OLIVEIRA, 2008). Essa expansão da cana, como se pode observar não só no Paraná mas também em outros Estados, vem em detrimento da produção de alimentos.

Outro fato que merece atenção é a mobilidade rural-urbana decorrente destes arrendamentos. O pequeno proprietário que, na condição de dono das suas terras, tinha lá suas cabeças de gado, tinha o seu leite, tinha suas carnes e poderia produzir os demais alimentos para o sustento de sua família, na cidade, nada disso ele teria. O sustento da sua família será adquirido nos mercados e demais serviços de consumo coletivo, como água e luz, ele também teria que pagar. Ou seja, saindo do meio rural, suas despesas aumentarão e, quase sempre, no fim das contas, o pagamento advindo do arrendamento de suas terras acaba não sendo suficiente para manter sua família. Dificilmente este trabalhador 
conseguirá um trabalho remunerado na cidade, pois geralmente predomina a baixa escolaridade nesta classe de trabalhadores no Brasil. Porém, esta conscientização é difícil de ser alcançada, pois, na maioria das vezes, as usinas tratam estas questões com profissionalismo e pessoas treinadas, iludindo o proprietário de terras que vê no arrendamento a melhor opção para sua sobrevivência e de sua família, destituindo-o dos meios de produção da terra.

O avanço do agronegócio canavieiro com as suas possíveis implicações refletirá principalmente no Noroeste Paranaense, pois fala-se muito em um zoneamento ecológico natural, que leva em consideração as características físicas do solo, mas que ainda não é realidade. Enquanto isso, a região continua sendo explorada pelo capitalismo das corporações. Tormena (2007) sinalizava que a cana-de-açúcar expandirá no Noroeste, pelas áreas de solos arenosos, onde se desenvolve a pecuária. Temos indícios já, da cana-de-açúcar estar ocupando grandes áreas agrícolas de diversos municípios da região. A Mesorregião Noroeste engloba 61 municípios, somando aproximadamente 630.000 habitantes.

A figura 3 apresenta a área ocupada com a lavoura canavieira na Mesorregião Noroeste no ano de 2008. É possível perceber que a cultura está presente em quase todos os municípios que compreendem a Mesorregião, e em apenas 7 localidades, como mostra a figura, o cultivo da cana não é praticado. Percebe-se que em 9 municípios a cana-de-açúcar ocupa mais de 30\% da área municipal. Essa concentração leva ao detrimento da policultura e da agricultura familiar como salientado anteriormente, causando diversos impactos no âmbito local quando a questão refere-se à alimentação humana.

Como já destacado, nestes municípios os cultivos destinados à alimentação humana vêm diminuindo. Com isso, estas localidades terão que buscar essa produção em outras cidades. Isso agrega valor no preço final do produto, encarecendo muitas vezes os preços dos alimentos e exacerbando os problemas sociais da população mais carente. 


\section{Mesorregião}

Noroeste Paranaense

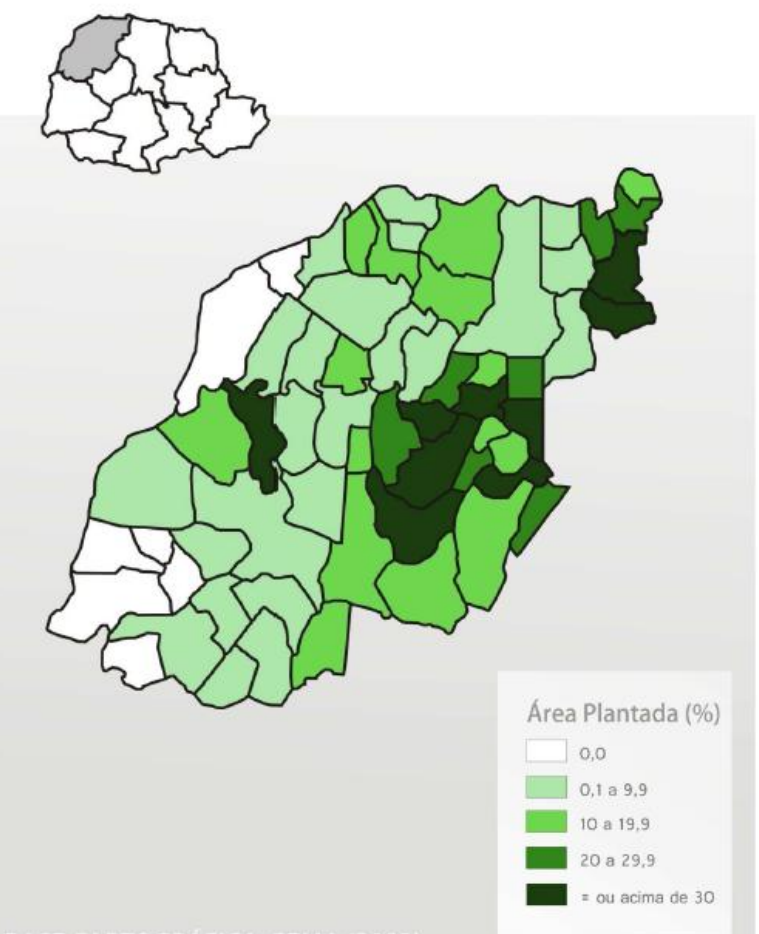

2008.

Figura 3- Noroeste Paranaense, área municipal ocupada com a lavoura canavieira no ano de Fonte: RIBEIRO, 2001.

Por meios de comparação, apresentamos a seguir duas localidades da Mesorregião Noroeste onde a gramínea ocupa mais de 30\% da área municipal. Posteriormente, serão apresentadas algumas informações acerca da produtividade agrícola dos municípios. Assim, será possível perceber que, conforme a área plantada com cana-de-açúcar aumenta, diminui áreas plantadas com outros cultivos.

Os municípios escolhidos foram São Tomé e Rondon. As informações foram baseadas nos dados do censo agropecuário do Instituto Brasileiro de Geografia e Estatística (IBGE), e como escala temporal utilizou-se os anos de 2000 a 2009.

O Município de São Tomé, como se pode observar nos Quadros 1 e 2, apresenta uma produção agrícola pouco diversificada, sendo as que mais se destacavam em 2009 a cana-de-açúcar, a mandioca, o milho, o soja, o trigo e a laranja. Contudo, só a cana de açúcar ocupava 9.534 hectares. Levando em consideração que todo o perímetro municipal de São Tomé tem aproximadamente 
21.862 hectares, a área ocupada com uma só cultura, no caso a cana-de-açúcar, dispõe de aproximadamente $46 \%$ de todo o perímetro.

Percebe-se que ao longo dos anos 2000 a cana-de-açúcar sempre ocupou grandes áreas agrícolas no município de São Tomé, tendo baixas oscilações entre algumas safras, mas sempre ocupando grandes áreas agrícolas. Já em alguns casos, como o arroz, no ano de 2000 a cultura ocupou uma área de apenas 10 hectares, o que já era muito pouco quando se trata de uma produção que se destina à alimentação humana e, a partir de 2004, a cultura deixou de existir no município. O feijão, que no ano de 2000 era cultivado em 110 hectares, foi perdendo espaço agrícola até chegar à apenas 6 hectares em 2009.

Quadro 1- Município de São Tomé, evolução da área plantada com lavoura temporária, 2000 a 2009.

\begin{tabular}{|l|r|r|r|r|r|r|r|r|r|r|}
\hline \multicolumn{7}{|c|}{ Área plantada (Hectares) } \\
\hline \multirow{2}{*}{ Lavoura temporária } & \multicolumn{7}{|c|}{ Ano } \\
\cline { 2 - 13 } & 2000 & 2001 & 2002 & 2003 & 2004 & 2005 & 2006 & 2007 & 2008 & 2009 \\
\hline Abacaxi & - & - & - & - & - & - & - & 25 & 25 & 25 \\
\hline Amendoim (em casca) & 3 & 3 & 4 & - & - & - & 5 & 5 & 8 & 5 \\
\hline Arroz (em casca) & 10 & 10 & 10 & 10 & - & - & - & - & - & - \\
\hline Aveia (em grão) & - & - & - & - & 100 & 40 & - & - & - & - \\
\hline Batata-doce & 1 & - & - & - & - & - & - & - & - & - \\
\hline Cana-de-açúcar & 7.530 & 7.813 & 7.474 & 8.906 & 8.769 & 9.055 & 9.311 & 9.779 & 10.200 & 9.534 \\
\hline Feijão (em grão) & 110 & 120 & 80 & 30 & 47 & 35 & 60 & 50 & 12 & 6 \\
\hline Mamona (baga) & 5 & 3 & - & - & - & - & - & - & - & - \\
\hline Mandioca & 1.303 & 1.303 & 903 & 400 & 900 & 1.000 & 380 & 470 & 400 & 603 \\
\hline Melancia & 1 & 1 & 2 & 3 & 3 & 4 & 5 & 3 & 3 & 3 \\
\hline Milho (em grão) & 1.263 & 2.100 & 1.500 & 2.050 & 1.850 & 1.520 & 2.650 & 3.100 & 1.650 & 1.620 \\
\hline Soja (em grão) & 1.245 & 1.300 & 1.800 & 2.700 & 2.900 & 2.900 & 2.500 & 1.800 & 1.700 & 1.500 \\
\hline Sorgo (em grão) & - & - & - & - & 50 & - & - & - & - & - \\
\hline Tomate & 1 & 1 & 3 & 3 & 2 & - & - & - & - & - \\
\hline Trigo (em grão) & 150 & 150 & 400 & 300 & 150 & 200 & 250 & 250 & - & 260 \\
\hline
\end{tabular}

Fonte: RIBEIRO, 2011.

Como se pode perceber, as atividades agrícolas que mais encontram destaque em São Tomé são aquelas pertencentes à lavoura temporária. A lavoura permanente como apresenta o Quadro 2 não dispõe de tantos cultivos, e os que mais se destacam são a laranja e o café. Este último também perdeu áreas agrícolas e em 2000 ocupava uma área de 852 hectares e em 2009 esse número caiu para 98 , ou seja, uma queda de aproximadamente $89 \%$. 
Quadro 2- Município de São Tomé, evolução da área plantada com lavoura permanente, 2000 a 2009.

\begin{tabular}{|l|c|c|c|c|c|c|c|c|c|c|}
\hline \multicolumn{10}{|c|}{ Área plantada (Hectares) } \\
\hline \multirow{2}{*}{ Lavoura permanente } & \multicolumn{10}{|c|}{ Ano } \\
\cline { 2 - 15 } & 2000 & 2001 & 2002 & 2003 & 2004 & 2005 & 2006 & 2007 & 2008 & 2009 \\
\hline Abacate & 3 & 3 & - & - & - & - & - & - & - & - \\
\hline Café (em grão) & 852 & 652 & 634 & 355 & 321 & 210 & 170 & 119 & 135 & 98 \\
\hline Goiaba & 30 & 30 & 37 & 30 & 30 & 30 & 30 & 30 & 30 & 30 \\
\hline Laranja & 73 & 73 & 73 & 66 & 71 & 98 & 98 & 117 & 196 & 215 \\
\hline Manga & 15 & 15 & 15 & 15 & 15 & 15 & 15 & 5 & 5 & 5 \\
\hline Maracujá & - & - & - & - & - & - & - & 3 & 3 & 3 \\
\hline Palmito & - & - & - & 10 & 10 & 10 & 12 & 12 & 12 & 12 \\
\hline
\end{tabular}

Fonte: RIBEIRO, 2011.

No município de Rondon, a realidade é muito semelhante. A atividade agrícola é pouco diversificada, tendo a cana-de-açúcar como o principal cultivo. Considerando todo o perímetro municipal de Rondon, que compreende 55.608,60 hectares e, destes a cana-de-açúcar provém de 16.378 hectares (IBGE, 2009), aproximadamente $35 \%$ de todo o perímetro destina-se a apenas um cultivo. As demais culturas são produzidas em poucas áreas agrícolas. Os Quadros a seguir apresentam as atividades agrícolas de Rondon, e assim como em São Tomé, a cana-de-açúcar ganhou espaços agrícolas e, em contra partida, outras culturas perderam espaços sendo que algumas deixaram de existir, como o algodão, mamona, e dentre outros da lavoura permanente.

Quadro 3- Município de Rondon, evolução da área plantada com lavoura temporária- ano 2000 a 2009.

\begin{tabular}{|c|c|c|c|c|c|c|c|c|c|c|}
\hline \multirow{2}{*}{ Lavoura Temporária } & \multicolumn{10}{|c|}{ Área Plantada (hectares) } \\
\cline { 2 - 14 } & \multicolumn{10}{|c|}{ Ano } \\
\cline { 2 - 14 }$y$ & 2000 & 2001 & 2002 & 2003 & 2004 & 2005 & 2006 & 2007 & 2008 & 2009 \\
\hline Abacaxi & - & 2 & 2 & - & 2 & - & - & 3 & - & - \\
\hline $\begin{array}{c}\text { Algodão herbáceo (em } \\
\text { caroço) }\end{array}$ & - & 68 & 5 & 5 & 70 & 80 & 12 & - & - & - \\
\hline Amendoim (em casca) & 40 & 50 & 30 & 20 & 40 & 40 & 40 & 40 & 5 & 3 \\
\hline Arroz (em casca) & 110 & 110 & 110 & 87 & 37 & 17 & 27 & 30 & 24 & 10 \\
\hline Batata-doce & 2 & 2 & 2 & 2 & - & - & - & 2 & 2 & - \\
\hline Cana-de-açúcar & 6.014 & 8.747 & 10.861 & 12.078 & 13.285 & 14.901 & 15.220 & 18.604 & 19.988 & 16.378 \\
\hline Feijão (em grão) & 320 & 145 & 130 & 190 & 160 & 130 & 150 & 140 & 20 & 15 \\
\hline Mamona (baga) & 25 & 15 & - & - & - & - & - & - & - & - \\
\hline Mandioca & 1.102 & 710 & 812 & 500 & 1.000 & 1.200 & 900 & 1.000 & 500 & 650 \\
\hline Melancia & 2 & 2 & 2 & - & - & 5 & 2 & 4 & - & - \\
\hline Milho (em grão) & 1.829 & 1.950 & 1.300 & 1.350 & 600 & 500 & 650 & 500 & 460 & 480 \\
\hline Soja (em grão) & 350 & 620 & 600 & 750 & 900 & 800 & 800 & 250 & 100 & 225 \\
\hline Sorgo (em grão) & - & - & - & - & 15 & 20 & - & - & - & - \\
\hline
\end{tabular}

Fonte: RIBEIRO, 2011. 
Percebe-se que em 2000 a cana-de-açúcar era cultivada em 6.014 hectares. Em 2009 a gramínea já ocupava 16.378 hectares, ou seja, obteve um aumento de área de aproximadamente $272 \%$. Essa expansão se deu às custas do detrimento dos demais cultivos, pois, como pode-se observar, quase todos perderam espaços, salvos os cultivos de laranja e da borracha (aumentou timidamente de 15 hectares para 33 ha). A laranja, em 2000 ocupava um espaço agrícola de 115 hectares, e em 2009 aumentou para 250 hectares.

Quadro 4- Município de Rondon, evolução da área plantada com lavoura permanente- ano 2000 a 2009.

\begin{tabular}{|c|c|c|c|c|c|c|c|c|c|c|}
\hline \multirow{3}{*}{ Lavoura Permanente } & \multicolumn{10}{|c|}{ Área Plantada } \\
\hline & \multicolumn{10}{|c|}{ Ano } \\
\hline & 2000 & 2001 & 2002 & 2003 & 2004 & 2005 & 2006 & 2007 & 2008 & 2009 \\
\hline Abacate & 10 & 14 & 14 & 14 & 14 & 14 & 7 & 7 & 7 & 3 \\
\hline Banana (cacho) & 3 & 3 & 3 & - & - & - & - & 1 & 1 & 1 \\
\hline Borracha (látex coagulado) & - & 15 & 15 & 15 & 15 & 15 & 15 & 36 & 36 & 33 \\
\hline Café (em grão) & 1.240 & 975 & 1.248 & 760 & 475 & 455 & 460 & 180 & 186 & 119 \\
\hline Caqui & 1 & 2 & 2 & 2 & 2 & - & - & - & - & - \\
\hline Coco-da-baía & - & 4 & 4 & 4 & 4 & 4 & 4 & 4 & 4 & 4 \\
\hline Laranja & 115 & 91 & 105 & 104 & 95 & 104 & 104 & 175 & 203 & 250 \\
\hline Limão & 1 & 1 & 1 & 1 & 1 & 1 & 1 & 1 & 1 & 1 \\
\hline Manga & 4 & 4 & 4 & 4 & 4 & 4 & - & 2 & 2 & - \\
\hline Maracujá & - & - & - & - & 1 & 4 & 8 & 4 & 4 & - \\
\hline Palmito & - & 2 & 2 & 2 & - & - & - & 2 & 2 & 2 \\
\hline Tangerina & 3 & 3 & 3 & 3 & 3 & - & - & - & - & - \\
\hline
\end{tabular}

Fonte: RIBEIRO, 2011.

Esses e dentre outros são reflexos no espaço agrícola brasileiro, onde a monocultura da cana-de-açúcar expande-se às avessas. Tanto em São Tomé como também em Rondon apresentam Unidades de Produção do setor sucroalcooleiro. As usinas, inseridas nestas pequenas localidades do Noroeste Paranaense acabam atrelando pra si as políticas públicas locais, facilitando o desenvolvimento de suas atividades nestas localidades. Com isso a alienação e a manipulação por parte dos agentes canavieiros, pautadas nas buscas constantes de terras, tem-se desencadeados conflitos em ambos os lados: entre os próprios agentes do agronegócio que vêem suas culturas perderem espaços agrícolas; entre os pequenos e médios agricultores que ficam "ilhados" em meio canavial; e a sociedade em geral que fica atrelada aos serviços oferecidos pelo setor sucroalcooleiro, que na maioria são trabalhos exaustivos e de alta periculosidade. 
Sakamoto (2001) aponta que o engenho ainda existe. A casa grande e a senzala também. As relações humanas só ganharam uma roupagem mais nobre. E assim a cana-de-açúcar vai reproduzindo no País as históricas contradições sociais já tão expressivas na sociedade brasileira.

\section{Considerações Finais}

Esse trabalho esboçou algumas considerações sobre a atividade canavieira no Norte Paranaense. Ainda há muito que estudar e acompanhar de perto os impactos na sociedade paranaense e na brasileira em geral, decorrente da expansão desta atividade no país. Se, por um lado, o Brasil avançou nas relações capitalistas no meio rural, tecnificando as atividades agrícolas por meio de subsídios e outras políticas governamentais, aumentando a produtividade e modernizando a produção nacional; por outro o país retrocedeu, principalmente no que diz respeito à produção alimentar, às pequenas propriedades policultoras e à erradicação da pobreza no campo. A mobilidade da população rural-urbana, após os anos 1960/70, aconteceu de maneira contraditória, gerando diversos problemas sociais em várias regiões do Brasil. Esse processo desencadeado, conhecido como êxodo rural, persiste na atualidade, inclusive nas áreas sucroalcooleiras, na medida em que a cana-de-açúcar expande-se no meio rural, gerando tensões e diversos conflitos no campo. Percebe-se que o tempo passou e a lógica que permeia as relações capitalistas no campo continua se reproduzindo.

A questão do detrimento da policultura e das atividades agrícolas destinadas à alimentação humana são apenas alguns reflexos da escala global no âmbito local. A corrida pelos recursos energéticos renováveis pelos países desenvolvidos e a constante busca pela redução dos combustíveis fósseis, causadores de diversos danos ambientais, têm como resultado, no Brasil, essa expansão desordenada da lavoura canavieira, trazendo consigo diversos problemas de ordem social como a precarização do trabalho e a expropriação de pequenos agricultores, bem como danos ambientais com as queimadas, poluição de rios, desertificação dos solos e outros. É preciso um olhar mais atento para as relações econômicas globais, e investigar as possíveis implicações destas 
relações no âmbito de escalas locais, ainda mais quando se trata de uma atividade que perdurou séculos se desenvolvendo às custas do regime de trabalho escravo no Brasil. Assim, o presente trabalho apresentou algumas consequências na produção do espaço geográfico rural no norte paranaense, a qual demanda por uma postura crítica frente à organização do sistema hegemônico que molda este território. Por isso, faz-se necessário, ainda, outras pesquisas que atentem para este tema, desvendando estratégias capitalistas que solapam com as propriedade policultoras locais.

\title{
Notas
}

\begin{abstract}
* Mestre em Geografia pela Universidade Estadual de Maringá e professor da rede Estadual de Ensino do Estado do Paraná. Integrante do Núcleo de Estudos de Mobilidade e Mobilização- NEMO/ UEM.

"Doutorando em Geografia pela Universidade Estadual de Maringá, professor da Universidade Tecnológica Federal do Paraná. Coordenador do Núcleo de Estudos de Mobilidade e Mobilização- NEMO, da Universidade Estadual de Maringá.
\end{abstract}

\section{Referências}

ENDLICH, Ângela Maria. Pensando os papéis e significados das pequenas cidades do Noroeste do Paraná. UNESP, Presidente Prudente, 2009, 357p.

IBGE, Disponível em:

<www.ibge.com.br> acesso em: agosto de 2011.

IANNI, Octávio. O Estado e capitalismo. Rio de Janeiro. Civilização Brasileira. 1965. 270p.

MARTINS, Marcos. Municípios do Norte Pioneiro querem limitar o cultivo de cana. Gazeta do Povo, Cambará, 15 abr. 2008, Caminhos do Campo, p. 4.

MINISTÉRIO DA AGRICULTURA. Zoneamento agroecológico da cana-deaçúcar. Rio de Janeiro. EMBRAPA. 2009. 55p.

NUNES, Osmar. Mandioca tenta segurar a cana. Gazeta do Povo, Paranavaí, 23 de out. 2007, Caminhos do Campo, página 4 a 5.

OLIVEIRA, Ariovaldo Umbelino. Agrocombustíveis e produção de alimentos. Folha de São Paulo, São Paulo, 17 abr. 2008. Opinião.

RIBEIRO, Vitor Hugo. O avanço do setor sucroalcooleiro do Paraná: dos engenhos às usinas. 2008. 60 f. Trabalho de conclusão de curso (Graduação em Geografia). Universidade Estadual de Maringá, Maringá, 2008.

TAMOIOS. ANO VII. № 2, 2011 - ISSN 1980-4490 
RIBEIRO, Vitor Hugo. Mobilidade forçada e exploração da força de trabalho: um olhar para os trabalhadores da cana-de-açúcar do Noroeste Paranaense. 2011. 174p. Dissertação (Mestrado em Geografia). Programa de Pós- Graduação em Geografia. Universidade Estadual de Maringá. Maringá.

RIBEIRO, Vitor Hugo, ROCHA, Márcio Mendes. A mobilidade centrada no trabalho, e os trabalhadores da cana da mesorregião noroeste Paranaense: o caso de Porecatu e Astorga In: IV Congresso Internacional de História. Maringá, 2009. p.793 - 803 .

RIBEIRO, Vitor Hugo, ROCHA, Márcio Mendes. A Produção canavieira no espaço rural do Paraná, e a intensificação do setor sucroalcooleiro sob o olhar das políticas públicas voltadas ao etanol brasileiro In: VIII Simpósio de Geografia- SIMGEOTerritório e Paisagem Redimensionados pela Expansão da Cana-de-açúcar. 2010, Quirinópolis- GO: UEG. p.1-21.

SALVADOR, Fabíola. Área plantada de cana cresce $9,2 \%$, para 8,1 milhões de hectares. 2010. Disponível em:

$<$ http://agricultura.ruralbr.com.br/noticia/2010/04/area-plantada-de-cana-cresce-9-2para-8-1-milhoes-de-hectares-2888234.html> acesso em: agosto de 2011.

SAKAMOTO, L. O Engenho resiste.

Disponível em: http://www.reporterbrasil.com.br/exibe.php?id=13

Acesso em: janeiro/2011.

SANTOS, Milton. A natureza do espaço: técnica e tempo, razão e emoção. $4^{a}$ edição. São Paulo. USP, 2006, 259p.

Economia espacial. $2^{2}$ edição. São Paulo: Edusp, 2007. 204p.

TEIXEIRA, Wilson Antonio. As Transformações no Espaço Agrário do Paraná, com a introdução da Agricultura Energética Canavieira. Mestrado, UNESP, Rio Claro, 1988, 281p.

. O processo de desenvolvimento geoeconômico do complexo agroindustrial cooperativista na mesorregião Norte Central paranaense. 2002, 343f. Tese (Doutorado em Geografia) - Faculdade de Ciências e Tecnologia, Universidade Estadual Paulista, Presidente Prudente.

TORMENA, Anísio. A Cana vai avançar sobre a pecuária. O Diário do Norte do Paraná, Maringá,10 mai. 2007. Cidades, p. A8. 